\title{
Proxy Respondent
}

National Cancer Institute

\section{Source}

National Cancer Institute. Proxy Respondent. NCI Thesaurus. Code C142652.

A person in a clinical trial other than the subject who provides responses about the subject on their behalf, but not as an observer. 